\title{
Produção e valor nutritivo do capim-tanzânia fertilizado com nitrogênio e fósforo
}

\author{
Neusete Maria da Silva Patês ${ }^{1}$, Aureliano José Vieira Pires ${ }^{2}$, Gleidson Giordano Pinto de \\ Carvalho $^{3}$, Aline Cardoso Oliveira ${ }^{4}$, Marcelle Pereira Foncêca ${ }^{5}$, Cristina Mattos Veloso ${ }^{2}$ \\ 1 Programa de Pós-graduação em Zootecnia, Universidade Estadual do Sudoeste da Bahia, Praça Primavera, CEP: 45.700.000, Itapetinga-BA \\ 2 DTRA/UESB, Campus Juvino Oliveira, Itapetinga-BA. Pesquisador do CNPq. \\ 3 Programa de Pós-graduação em Zootecnia - UFV, Viçosa, MG. Bolsista do CNPq. \\ ${ }^{4}$ Programa de Pós-graduação em Zootecnia - UFV, Viçosa, MG. \\ ${ }^{5}$ Curso de graduação em Zootecnia, UESB, Itapetinga, BA.
}

RESUMO - O experimento foi realizado em casa de vegetação com o objetivo de avaliar o efeito da adubação nitrogenada e fosfatada sobre a produção de matéria seca (MS) da parte aérea e das raízes, o teor e a produção de proteína bruta (PB) e de fibra em detergente neutro (FDN). Utilizou-se o delineamento experimental inteiramente casualizado em esquema fatorial $4 \times 2$, composto de quatro doses de nitrogênio $\left(0,50,100\right.$ e $\left.150 \mathrm{mg} / \mathrm{dm}^{3}\right)$ e duas doses de $\mathrm{P}_{2} \mathrm{O}_{5}\left(0\right.$ e $\left.45 \mathrm{mg} / \mathrm{dm}^{3}\right)$ com quatro repetições. As sementes da gramínea foram estabelecidas em vasos com capacidade de 6,3 L, de modo que, após desbaste, permaneceram três plantas por vaso. Observou-se interação entre doses de nitrogênio e a produção de MS da parte aérea e de raízes. As produções estimadas de MS da parte aérea obtidas com associação de nitrogênio $\left(0,50,100\right.$ e $\left.150 \mathrm{mg} / \mathrm{dm}^{3}\right)$ e $\mathrm{P}_{2} \mathrm{O}_{5}\left(45 \mathrm{mg} / \mathrm{dm}^{3}\right)$ foram de 4,7; 18,5; 32,3 e 46,1 g/vaso e a produção de MS de raízes, de 6,3; 41,7; 77,1 e 112,5 g/vaso, respectivamente. As doses de nitrogênio e fósforo não influenciaram o teor de FDN, mas afetaram o de PB, que foi maior nas doses mais altas de nitrogênio sem adição de fósforo. A adubação com doses crescentes de nitrogênio associadas a $\mathrm{P}_{2} \mathrm{O}_{5}$ aumenta a produção e o valor nutritivo do capim-tanzânia.

Palavras-chave: gramínea, matéria seca, nutrientes, Panicum maximum, solo

\section{Production and nutritive value of tanzaniagrass fertilized with nitrogen and phosphorus}

\begin{abstract}
The experiment was conducted in a greenhouse and aimed to evaluate the effect of $\mathrm{N}$ and $\mathrm{P}$ fertilization on dry matter (DM) production of shoots and roots, crude protein (CP) production and concentration, and neutral detergent fiber (NDF) concentration of Tanzania grass. It was used a completely randomized experimental design in a $4 \times 2$ factorial scheme, being four $\mathrm{N}$ doses $\left(0,50,100\right.$, and $\left.150 \mathrm{mg} \mathrm{N} / \mathrm{dm}^{3}\right)$ and two doses of $\mathrm{P}_{2} \mathrm{O}_{5}\left(0\right.$ and $\left.45 \mathrm{mg}_{2} \mathrm{O}_{5} / \mathrm{dm}^{3}\right)$, with four replicates. It was used pots with $6.3 \mathrm{~L}$ capacity, in which the grass seeds were sawed, leaving three plants in each pot. It was observed interaction among $\mathrm{N}$ and $\mathrm{P}$ doses for shoot and root DM production. Shoot DM production at the $45 \mathrm{mg}$ of $\mathrm{P}_{2} \mathrm{O}_{5} / \mathrm{dm}^{3}$ dose were $4.7,18.5,32.3$, and $46.1 \mathrm{~g} /$ pot whereas root production at the same $\mathrm{P}$ level were 6.3, 41.7, 77.1, and $112.5 \mathrm{~g} / \mathrm{pot}$, for $0,50,100$, and $150 \mathrm{mg}$ of $\mathrm{N} / \mathrm{dm}^{3}$, respectively. There was no difference for NDF concentration as a function of $\mathrm{N}$ and $\mathrm{P}$ doses, but $\mathrm{CP}$ concentration increased with increasing $\mathrm{N}$ fertilization when $\mathrm{P}$ was not added. Increasing $\mathrm{N}$ fertilization in the presence of $\mathrm{P}$ fertilization increased the production and nutritive value of tanzaniagrass.
\end{abstract}

Key Words: dry matter, grass, nutrients, Panicum maximum, soil

\section{Introdução}

De modo geral, cultivares de Panicum maximum apresentam alta resposta à adubação com fósforo (Gheri et al., 2000). No entanto, Monteiro (1995) evidenciou que a recomendação de nitrogênio para aplicação em pastagens de Panicum maximum varia de 50 a 300 kg/ha/ano. Baixos níveis desse nutriente têm sido aplicados para evitar a degradação desta forrageira na pastagem, enquanto níveis mais altos são aconselháveis quando o objetivo é aumentar a produtividade da pastagem e do animal, evidenciando que, à medida que se aumenta a fertilização nitrogenada, torna-se necessário o parcelamento dessa adubação. 
A produção de matéria seca (MS) das gramíneas tropicais está diretamente relacionada à aplicação de níveis crescentes de nitrogênio (Quadros et al., 2002). Por outro lado, o rendimento forrageiro, em condições de baixos teores de fósforo disponível no solo, pode não responder à adubação com nitrogênio. Esse é um dos maiores problemas no estabelecimento e na manutenção de pastagens, pois, além da grande importância no estabelecimento inicial das espécies forrageiras, o fósforo favorece o desenvolvimento da parte aérea e das raízes (Belarmino et al., 2003).

Além da escolha de gramíneas forrageiras com potencial para produção de forragem e com bom valor nutritivo, é necessária também a compreensão dos mecanismos morfofisiológicos e de sua interação com o ambiente (Machado et al., 1998). Entre os cultivares do gênero Panicum, o capim-tanzânia possui essas características e constitui uma forrageira altamente promissora para utilização em pastejo (Cecato et al., 2001).

O manejo de corte da forrageira é um fator que modifica tanto a produção quanto a qualidade de forragem. Dantas Neto et al. (2000) relataram que, além da fertilidade, a época do primeiro corte e o número de cortes influenciam a produção e a qualidade da forrageira. Cortes em intervalos menores resultam em baixa produção de MS (Alvim et al., 1998), porém de valor nutritivo maior, em comparação a cortes a intervalos maiores, que resultam em produções mais elevadas e de qualidade inferior.

O conhecimento dos teores de MS, proteína bruta (PB), fibra e demais componentes é fundamental para avaliações preliminares de uma planta promissora (Gerdes et al., 2000), pois permite estimar o valor nutritivo da forrageira.

Este trabalho foi conduzido para avaliar a produção e a composição química do capim-tanzânia fertilizado com nitrogênio e fósforo.

\section{Material e Métodos}

O experimento foi realizado em casa de vegetação na Universidade Estadual do Sudoeste da Bahia, no Campus Juvino Oliveira, na cidade de Itapetinga, Bahia, no período de setembro de 2004 a março de 2005. O solo utilizado, proveniente do Campus da UESB de Itapetinga, foi coletado na camada de 0 a $20 \mathrm{~cm}$ de profundidade e classificado como Latossolo vermelho - amarelo distrófico. Inicialmente, foi destorroado e cessado em peneira com malha de $4 \mathrm{~mm}$, homogeneizado e, posteriormente, analisado quanto às características químicas, físicas e de matéria orgânica: $\mathrm{pH}=5,8, \mathrm{P}=1 \mathrm{mg} / \mathrm{dm}^{3}, \mathrm{~K}=0,10 \mathrm{mg} / \mathrm{dm}^{3}, \mathrm{H}=$ $1,5 \mathrm{cmol}_{\mathrm{C}} / \mathrm{dm}^{3}, \mathrm{Al}=0,0 \mathrm{cmol}_{\mathrm{C}} / \mathrm{dm}^{3}, \mathrm{Ca}=5,0 \mathrm{cmol}_{\mathrm{C}} / \mathrm{dm}^{3}$,
$\mathrm{Mg}=2,5 \mathrm{cmol}_{\mathrm{c}} / \mathrm{dm}^{3}, \mathrm{t}=7,6 \mathrm{cmol}_{\mathrm{C}} / \mathrm{dm}^{3}, \mathrm{CTC}=9,1 \mathrm{cmol}_{\mathrm{C}} / \mathrm{dm}^{3}$, $\mathrm{SB}=7,6 \mathrm{cmol}_{\mathrm{C}} / \mathrm{dm}^{3}, \mathrm{~V}=84 \%, \mathrm{MO}=29 \mathrm{dag} / \mathrm{kg}$ e argila $=$ $230 \mathrm{~g} / \mathrm{kg}$.

O solo foi corrigido para o plantio com adubação potássica utilizando-se cloreto de potássio na quantidade de $32 \mathrm{mg} / \mathrm{dm}^{3}$ de $\mathrm{K}_{2} \mathrm{O}$ por vaso, na forma de $\mathrm{KCl}$, para garantir o perfeito crescimento das plantas durante o período experimental (Cantarutti et al., 1999).

Utilizou-se um esquema fatorial $4 \times 2$, composto de quatro doses de nitrogênio $\left(0,50,100\right.$ e $150 \mathrm{mg} / \mathrm{dm}^{3}$ na forma de uréia) e duas doses de $\mathrm{P}_{2} \mathrm{O}_{5}\left(0\right.$ e $45 \mathrm{mg} / \mathrm{dm}^{3}$, na forma de superfosfato simples), em delineamento experimental inteiramente casualizado, com quatro repetições.

Foram utilizados vasos de polietileno contendo $6 \mathrm{~L}$ de terra, onde foram semeadas no dia 13 de setembro de 2004 sementes de capim-tanzânia com valor cultural de $24 \%$. Após desbaste, foram mantidas três plantas uniformes por vaso. As plantas foram irrigadas quatro vezes por semana, com $600 \mathrm{~mL}$ de água deionizada, mantendo-se o solo com aproximadamente $80 \%$ de sua capacidade de campo e garantindo boas condições de crescimento.

O superfosfato simples foi aplicado juntamente com o cloreto de potássio no plantio e a uréia, a cada corte, parcelada em três doses: a primeira no corte de uniformização; a segunda no primeiro corte; e a terceira no segundo corte. Os nutrientes foram diluídos em $1 \mathrm{~L}$ de água e aplicados nos vasos.

Aos 46 dias após o plantio, foi realizado o corte de uniformização à altura de $5 \mathrm{~cm}$ acima do solo e 35 dias após a uniformização, foi realizado o primeiro dos três cortes da parte aérea, todos com o mesmo intervalo e a uma altura média de $20 \mathrm{~cm}$ do solo.

A produção de MS foi determinada por meio da soma dos três cortes. As amostras da parte aérea foram coletadas, pesadas, processadas e posteriormente submetidas a análises para determinação dos teores de MS, proteína bruta (PB) e fibra em detergente neutro (FDN) (Silva \& Queiroz, 2002). Com o auxílio de peneiras, as raízes foram lavadas em água corrente e secas em estufa com circulação forçada a $55^{\circ} \mathrm{C}$.

Os resultados foram interpretados por meio de análise de variância $(\mathrm{P}<0,05)$ utilizando-se o programa estatístico SAEG, versão 8.1 (Ribeiro Jr., 2001) para verificar a significância do efeito das doses de nitrogênio, de $\mathrm{P}_{2} \mathrm{O}_{5}$ ou de suas interações. O efeito do nitrogênio foi avaliado por análise de regressão, por meio de polinômios ortogonais, pela decomposição da soma de quadrado de nitrogênio em efeitos linear, quadrático e cúbico. As doses de $\mathrm{P}_{2} \mathrm{O}_{5}$ foram comparadas pelo teste $\mathrm{F}$ a $5 \%$ de probabilidade. 


\section{Resultados e Discussão}

Verificou-se efeito da interação das doses de nitrogênio e de $\mathrm{P}_{2} \mathrm{O}_{5}$ sobre a produção de MS da parte aérea e de raízes. As doses crescentes de nitrogênio, sem aplicação de fósforo ( $0 \mathrm{mg}$ de $\mathrm{P}_{2} \mathrm{O}_{5}$ ), tiveram efeito quadrático (Figura 1) sobre a produção de MS da parte aérea. Estimada pela equação, a produção máxima de MS foi de 26,6 g/vaso e foi obtida na dose de $134,8 \mathrm{mg} / \mathrm{dm}^{3}$, um indicativo de que não é necessário aplicar doses de nitrogênio superiores a $134,8 \mathrm{mg} / \mathrm{dm}^{3}$ quando o solo apresenta apenas $1,0 \mathrm{mg} / \mathrm{kg}$. Contudo, produções superiores poderiam ser obtidas em solos com teor de fósforo superior a $1,0 \mathrm{mg} / \mathrm{kg}$.

As produções estimadas de MS com a combinação de $45 \mathrm{mg}$ de $\mathrm{P}_{2} \mathrm{O}_{5}$ foram de 4,7; 18,5; 32,3 e 46,1 g/vaso, respectivamente, nas doses de nitrogênio de $0,50,100$ e $150 \mathrm{mg} / \mathrm{dm}^{3}$, comprovando efeito linear positivo $(\mathrm{P}<0,05)$ (Figura 1). Esses resultados corroboram os obtidos por Gheri et al. (2000), que observaram aumento na produção de MS do capim-tanzânia com a aplicação de fósforo, o que demonstra o grande potencial de resposta desse capim à adubação nitrogenada e fosfatada.

A aplicação de fósforo não afetou a produção de MS da parte aérea nas doses de nitrogênio de 0 e $50 \mathrm{mg} / \mathrm{dm}^{3}$, cujos valores foram de 5,3 e 16,8 g/vaso sem a aplicação de $\mathrm{P}_{2} \mathrm{O}_{5}$ e de 5,1 e $17,5 \mathrm{~g} /$ vaso com a aplicação de $\mathrm{P}_{2} \mathrm{O}_{5}\left(45 \mathrm{mg} / \mathrm{dm}^{3}\right)$. Nas doses de nitrogênio de 100 e $150 \mathrm{mg} / \mathrm{dm}^{3}$, as duas doses de $\mathrm{P}_{2} \mathrm{O}_{5}$ diferiram entre si: com o aumento do suprimento de nitrogênio de 50 para $150 \mathrm{mg} / \mathrm{dm}^{3}$ combinado com $\mathrm{P}_{2} \mathrm{O}_{5}$ na dose de $45 \mathrm{mg} / \mathrm{dm}^{3}$, obteve-se acréscimo na produção de MS de 40,7 g/vaso, que corresponde a aumento de $754 \%$ em comparação à produção obtida sem aplicação de fósforo (5,4 g/vaso). Assim, o aumento da produtividade dessa

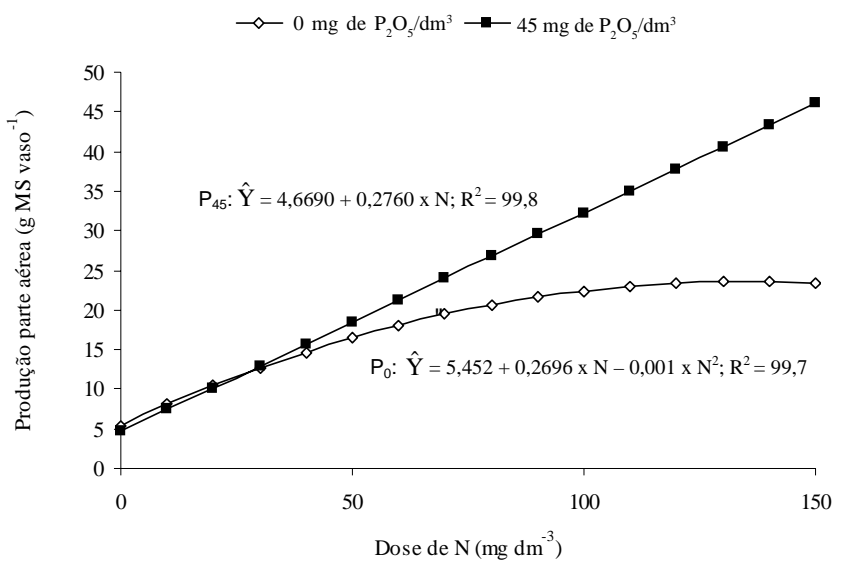

Figura 1 - Produção de matéria seca da parte aérea (g/vaso) do capim-tanzânia fertilizado com nitrogênio e fósforo. gramínea em resposta à adubação nitrogenada e fosfatada reforça a importância desses nutrientes para o aumento da produção de MS dessa forrageira. Segundo Ribeiro et al. (1999), entre os fatores que influenciam o valor nutritivo da planta forrageira, destaca-se a disponibilidade dos nutrientes no solo e suas interações. O nitrogênio, entre os nutrientes, é o principal responsável pelo aumento da produção de forragem (Sarmento et al., 2008).

O aumento da produção de MS observado neste trabalho com a aplicação de nitrogênio em combinação à maior dose de $\mathrm{P}_{2} \mathrm{O}_{5}\left(45 \mathrm{mg} / \mathrm{dm}^{3}\right)$ corrobora os resultados obtidos por Lira et al. (1994), que avaliaram a influência da fertilização com três doses de $\mathrm{P}_{2} \mathrm{O}_{5}(0,60$ e $120 \mathrm{~kg} / \mathrm{ha})$ e quatro doses de nitrogênio (0, 20, 40 e 60 kg/ha) sobre a produção de MS de Brachiaria decumbens e observaram respostas significativas à adubação quando utilizaram $20 \mathrm{~kg}$ de nitrogênio associados a $60 \mathrm{~kg}$ de $\mathrm{P}_{2} \mathrm{O}_{5}$. Esses autores observaram aumento de $82,6 \%$ na produção de MS, no entanto, a adubação com $\mathrm{P}_{2} \mathrm{O}_{5}$ (120 kg/ha) associado a nitrogênio (40 ou $60 \mathrm{~kg} / \mathrm{ha}$ ) aumentou para 5,5 e 6,6 kg/ha por corte, respectivamente.

Belarmino et al. (2003), em estudos sobre os efeitos da adubação com fósforo (0, 50, 100 e 150 kg/ha) e nitrogênio (0,100 e 200 kg/ha) sobre a produção do capim-tanzânia, verificaram que a presença de fósforo aumentou o rendimento de MS nas três doses de nitrogênio. Nas doses 0 e $200 \mathrm{~kg} / \mathrm{ha}$, observaram rendimentos de MS de 2,86 e $12,70 \mathrm{~kg} /$ ha para cada kg de $\mathrm{P}_{2} \mathrm{O}_{5}$ aplicado.

Costa (1995), estudando a produção do capim-elefante fertilizado com doses de nitrogênio de 0, 50 e $100 \mathrm{~kg} / \mathrm{ha} / \mathrm{ano}$, encontrou produções de MS de 20,62; 25,49 e 29,62 t/ha. Andrade et al. (2000) avaliaram sete doses de nitrogênio (20, $50,100,200,300,350$ e $380 \mathrm{~kg} / \mathrm{ha}$ ) e observaram efeito significativo do nitrogênio sobre a produção de MS, que variou de 2.549 a $4.731 \mathrm{~kg} / \mathrm{ha}$ e ocasionou aumento de $85,6 \%$ na produtividade.

Os resultados da análise de regressão revelaram efeito linear positivo das doses de nitrogênio sobre a produção de MS de raízes do capim-tanzânia, independentemente da dose de $\mathrm{P}_{2} \mathrm{O}_{5}$ (Figura 2). Na ausência de fósforo, a produção de raízes do capim-tanzânia foi inferior à obtida na presença de fósforo (Figura 2). Os valores encontrados foram de 12,2; 28,1; 33,0 e 47,5 g/vaso e com a adubação fosfatada, de 11,1; 35,5; 75,3 e 115,8 g/vaso, respectivamente, para as doses de nitrogênio de 0,50 , 100 e $150 \mathrm{mg} / \mathrm{dm}^{3}$. As médias obtidas com a adição de fósforo diferiram somente nas doses de nitrogênio de 100 e $150 \mathrm{mg} / \mathrm{dm}^{3}$, o que comprova o comportamento benéfico da fertilização nitrogenada e fosfatada, que promoveu aumento de MS de raízes de 0,71 g para cada miligrama de 


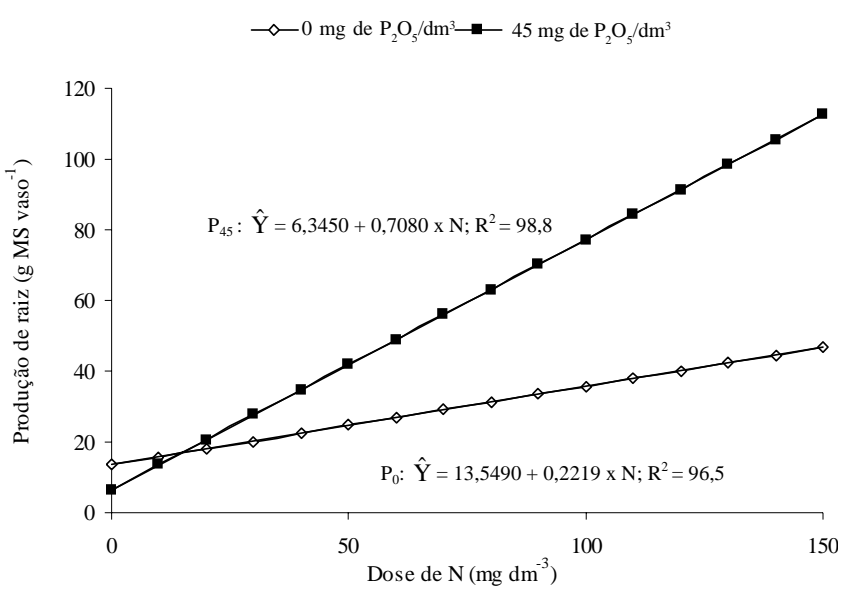

Figura 2 - Produção de matéria seca (MS) de raízes (g/vaso) do capim-tanzânia fertilizado com nitrogênio e $\mathrm{P}_{2} \mathrm{O}_{5}$.

nitrogênio aplicado, resultando em produção de MS de raízes 3,2 vezes maior que a obtida sem aplicação de fósforo, que promoveu aumento de 0,22 g.

As produções estimadas de MS de raízes sem a aplicação de $\mathrm{P}_{2} \mathrm{O}_{5}$ foram de 13,$5 ; 24,6 ; 35,7$ e $46,8 \mathrm{~g} /$ vaso e, com a associação de $45 \mathrm{mg}$ de $\mathrm{P}_{2} \mathrm{O}_{5}$, foram de 6,$3 ; 41,7 ; 77,1$ e 112,5 g/vaso, respectivamente, para as doses de nitrogênio de $0,50,100$ e $150 \mathrm{mg} / \mathrm{dm}^{3}$, o que comprova a importância do nutriente para a produção de raízes, uma vez que, com maior volume radicular, as plantas têm a capacidade de absorver maior quantidade de água e nutrientes. Além disso, a retomada do crescimento da parte aérea depende do suporte radicular da gramínea (Lavres Jr. \& Monteiro, 2003; Sarmento et al., 2008).

A aplicação de nitrogênio em gramíneas também foi estudada em sílica por Lavres Jr. \& Monteiro (2003), que avaliaram o sistema radicular do capim-mombaça adubado com nitrogênio nas doses de 28, 112, 210, 336 e 462 mg/L e constataram que, para obtenção do máximo comprimento total das raízes, seria necessário o fornecimento das doses mais elevadas. Esses autores verificaram ainda que o nitrogênio foi o principal nutriente modulador de respostas de raízes no capim-mombaça.

Ferrari Neto et al. (1994) avaliaram as limitações nutricionais dos capins colonião e braquiária e observaram que ausência de adubação com nitrogênio e fósforo reduziu o crescimento e afetou negativamente a produção de massa seca das raízes. A má distribuição do sistema radicular, concomitante ao pequeno volume, torna a planta mais susceptível a déficits hídricos, o que prejudica sua sustentação e restringe a exploração de nutrientes a um pequeno volume de solo. Entretanto, o fornecimento de nutrientes para as plantas afeta positivamente o crescimento das raízes e sua morfologia (Marschner, 1995).

Os efeitos de nitrogênio, fósforo e da interação desses nutrientes sobre o teor de FDN não foram significativos. Os valores de FDN obtidos com as doses de nitrogênio de 0 , 50,100 e $150 \mathrm{mg} / \mathrm{dm}^{3}$ foram de 73,$2 ; 72,0 ; 70$, 2 e $71,0 \%$, sem a aplicação de $\mathrm{P}_{2} \mathrm{O}_{5}$ e de 71,2, 71,8, 71,2 e 71,9\% com a aplicação de $\mathrm{P}_{2} \mathrm{O}_{5}$ na dose de $45 \mathrm{mg} / \mathrm{dm}^{3}$.

Neste estudo, os valores de FDN observados para o capim-tanzânia foram de 73,2; 72,0; 70,2 e 71\% nas doses de nitrogênio de $0,50,100$ e $150 \mathrm{mg} / \mathrm{dm}^{3}$, respectivamente, próximos aos obtidos por Gerdes et al. (2000), que analisando os teores de FDN de três forrageiras (Brachiaria brizantha, cv. Marandu; Setaria sphacelata; e Panicum maximum, cv. Tanzânia) amostradas aos 35 dias, aplicaram nitrogênio em cobertura (100 kg/ha) logo após o corte de rebaixamento e obtiveram concentrações médias de FDN de 68,$8 ; 72,7 ; 57,9$ e $62,3 \%$ para o capim-marandu, 70,7; 71,5; 58,7 e 62,9\% para o cultivar Setária e 74,7; 78,8; 70,7 e $67,7 \%$ para o capim-tanzânia.

O baixo valor nutritivo das forrageiras tropicais é freqüentemente mencionado na literatura e está associado ao reduzido teor de proteína bruta (PB) e de minerais e ao alto conteúdo de fibras. Com o amadurecimento da planta, a produção de componentes potencialmente digeríveis carboidratos solúveis, proteínas, minerais e outros conteúdos celulares - tende a decrescer. Ao mesmo tempo, as frações menos digeríveis, como lignina, celulose, hemicelulose protegidas, cutícula e sílica, aumentam, promovendo decréscimos na digestibilidade (Euclides, 1995). Desse modo, plantas com maiores teores de FDN teriam menor potencial de consumo voluntário, em virtude do efeito do enchimento ruminal.

A interação nitrogênio $\times$ fósforo influenciou os teores de proteína bruta, que não foram afetados pela dose de $45 \mathrm{mg}$ de $\mathrm{P}_{2} \mathrm{O}_{5}$, no entanto, apresentaram efeito quadrático na ausência de $\mathrm{P}_{2} \mathrm{O}_{5}$, Os teores de $\mathrm{PB}$ obtidos com adubação nitrogenada nas doses de 0,50,100 e $150 \mathrm{mg} / \mathrm{dm}^{3}$ sem adubação fosfatada foram de 4,9; 5,1; 5,7 e 6,7\%, respectivamente. Os valores encontrados sem adição de fósforo foram maiores que o valor médio estimado obtido com a aplicação de $\mathrm{P}_{2} \mathrm{O}_{5}$ na dose de $45 \mathrm{mg} / \mathrm{dm}^{3}$ (5\% de $\mathrm{PB})$. Esses resultados não têm uma causa isolada, ou seja, podem estar relacionados a uma combinação de fatores. Deve-se considerar inicialmente que a adubação nitrogenada sem a aplicação de $\mathrm{P}_{2} \mathrm{O}_{5}$ aumentou os teores de $\mathrm{PB}$, no entanto, nas situações de elevadas produções de MS (Figura 1), os teores de PB reduziram, o que pode estar associado ao maior acúmulo de MS, que causou o efeito de diluição do nitrogênio (Faquin, 1997). 
O rendimento de PB do capim-tanzânia foi influenciado pela interação nitrogênio $\times$ fósforo. No desdobramento da interação, as doses de nitrogênio em cada dose de $\mathrm{P}_{2} \mathrm{O}_{5}$ tiveram efeito significativo sobre o rendimento de $\mathrm{PB}$. As doses de nitrogênio, na ausência de $\mathrm{P}_{2} \mathrm{O}_{5}$ (Figura 3), tiveram efeito quadrático sobre o rendimento de PB e, de acordo com a equação, a dose de nitrogênio necessária para obtenção de rendimento de PB de $1.668 \mathrm{mg} /$ vaso seria de $216 \mathrm{mg} / \mathrm{m}^{3}$. No entanto, na dose $45 \mathrm{mg}$ de $\mathrm{P}_{2} \mathrm{O}_{5}$, o aumento foi linear crescente, indicando aumento de $13,07 \mathrm{mg} / \mathrm{dm}^{3}$ no teor de proteína bruta para cada mg de nitrogênio aplicado. Esse resultado reforça a necessidade de associação de fósforo à adubação nitrogenada para o rendimento de PB do capim-tanzânia (Figura 3). A maior produção de PB (mg/vaso) obtida com a aplicação de fósforo foi ocasionada pelo aumento na produção de MS/vaso, uma vez que os teores de PB foram de aproximadamente $5 \%$.

A aplicação de fósforo teve efeito somente quando combinada com nitrogênio na dose $150 \mathrm{mg} / \mathrm{dm}^{3}$, quando foram obtidos os melhores resultados de PB. Os teores de PB encontrados sem aplicação de fósforo foram de 262; 874; 1.236 e $1.548 \mathrm{mg} /$ vaso, enquanto com adubação fosfatada, foram de 246; 714; 1.344 e $2.214 \mathrm{mg} /$ vaso, respectivamente, para as doses de nitrogênio de 0, 50, 100 e $150 \mathrm{mg} / \mathrm{dm}^{3}$.

A influência positiva das doses de nitrogênio, sem aplicação de fósforo, sobre os teores de PB (\% de MS) corrobora os resultados descritos por Cecato et al. (2004), que observaram que os teores de PB aumentaram de forma linear com a adubação nitrogenada, mas não foram afetados pela adubação com fósforo, que teve apenas pequena influência no aumento dos teores de proteína bruta. Ressalta-se, entretanto, que a produção de PB, em mg/vaso, aumenta com a maior produção de MS,

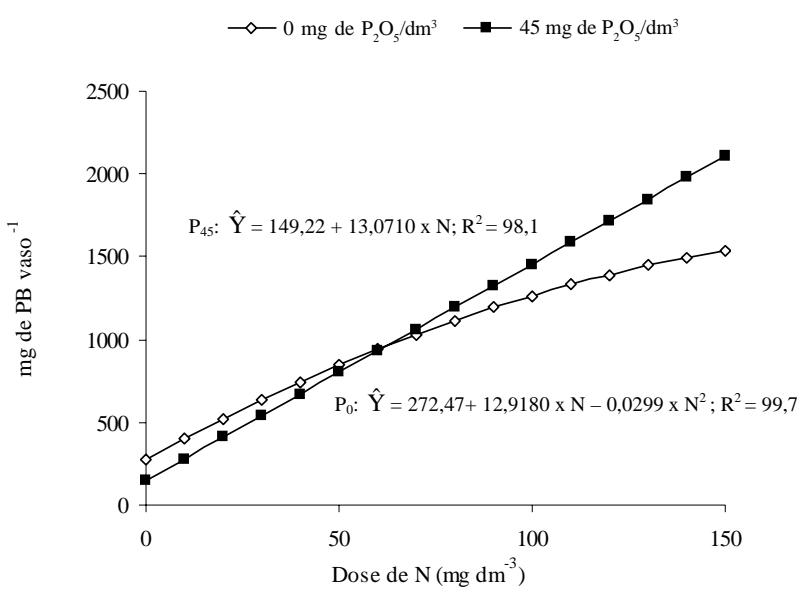

Figura 3 - Produção de proteína bruta (mg/vaso) do capimtanzânia fertilizado com nitrogênio e fósforo. favorecida pela adição de fósforo em associação ao nitrogênio.

\section{Conclusões}

A adição de nitrogênio $(0,50,100$ e 150 mg/dm³ $)$ combinado a $45 \mathrm{mg}$ de fósforo aumenta a produção de MS da parte aérea e de raízes do capim-tanzânia. Na ausência de fósforo, a produção máxima de parte área do capimtanzânia é obtida com a adubação nitrogenada na dose de $134,8 \mathrm{mg} / \mathrm{dm}^{3}$. A prática da adubação nitrogenada e fosfatada melhora a composição química do capimtanzânia, aumentando positivamente o seu valor nutritivo.

\section{Literatura Citada}

ALVIM, J.M.; XAVIER, D.F.; BOTREL, M.A. et al. Resposta do coast-cross (Cynodon dactylon (L) Pers.) a diferentes doses de nitrogênio e intervalos de cortes. Revista Brasileira de Zootecnia, v.27, n.5, p.833-840, 1998.

ANDRADE, A.C.; FONSECA, D.M.; GOMIDE, J.A. et al. Produtividade e valor nutritivo do capim-elefante cv. Napier sob doses crescentes de nitrogênio e potássio. Revista Brasileira de Zootecnia, v.29, n.6, p.1589-1595, 2000.

BELARMINO, M.C.J.; PINTO, J.C.; ROCHA, G.P. et al. Altura de perfilho e rendimento de matéria seca de capim Tanzânia em função de diferentes doses de superfosfato simples e sulfato de amônio. Ciência Agrotecnologia, v.27, n.4, p.879-885, 2003.

CECATO, U.; CASTRO, C.R.C.; CANTO, M.W. et al. Perdas de forragem em capim Tanzânia (Panicum maximum Jacq cv. Tanzânia-1) manejado sob diferentes alturas de pastejo. Revista Brasileira de Zootecnia, v.30, n.2, p.295-301, 2001.

CECATO, U.; PEREIRA, L.A.F.; JOBIM, C.C. et al. Influência das adubações nitrogenada e fosfatada sobre a composição químicobromatológica do capim Marandu (Brachiaria brizantha (Hochst) Stapf cv. Marandu). Acta Scientiarum Animal Sciences, v.26, n.3, p.409-416, 2004.

CANTARUTTI, R.B.; MARTINS, C.E.; CARVALHO, M.M. et al. Pastagens. In: RIBEIRO, A.C.; GUIMARÃES, P.T.G.; ALVAREZ V., V.H. (Eds.) Recomendações para o uso de corretivos e fertilizantes em Minas Gerais: $5^{\text {a }}$ aproximação. Viçosa: CFSEMG/UFV, 1999, p.332-341.

COSTA, N.L. Adubação nitrogenada e consorciação de capimelefante (Pennisetum purpureum cv. Cameroon) com leguminosas forrageiras tropicais. Pesquisa Agropecuária Brasileira, v.30, n.3, p.401-408, 1995.

DANTAS NETO, J.; SILVA, F.A.S.; FURTADO, D.A. et al. Influência da precipitação e idade da planta na produção e composição química do capim buffel. Pesquisa Agropecuária Brasileira, v.35, n.9, p.1867-1874, 2000.

EUCLIDES, V.P.B. Valor alimentício de espécies forrageiras do gênero Panicum. In: SIMPÓSIO SOBRE MANEJO DA PAstagem, 12., 1995, Piracicaba. Anais... Piracicaba: Fundação de Estudos Agrários Luiz de Queiroz, 1995, p.245247.

FAQUIN, V.; ROSSI, C.; CURI, N. et al. Nutrição mineral em fósforo, cálcio e magnésio do braquiarão em amostra de latossolo dos campos das vertentes sob influência de calagem e fontes de fósforo. Revista Brasileira de Zootecnia, v.26, n.6, p.1074-1082, 1997.

FERRARI NETO, J.; FAQUIN, V.; VALE, F.R. et al. Limitações nutricionais do Colonião (Panicum maximum Jacq.) e da Braquiária (Brachiaria decumbens Stapf.), em amostras de um 
latossolo do noroeste do Paraná: I. Produção de matéria seca e perfilhamento. Revista Brasileira de Zootecnia, v.23, n.4, p.538-551, 1994.

GERDES, L.; WERNER, J.C.; COLOZZA, M.T. et al. Avaliação de características de valor nutritivo das gramíneas forrageiras Marandu, Setária e Tanzânia nas estações do ano. Revista Brasileira de Zootecnia, v.29, n.4, p.955-963, 2000.

GHERI, E.O.; CRUZ, M.C.P.; FERREIRA, M.E. et al. Nível crítico de fósforo no solo para Panicum maximum Jacq. cv. Tanzânia. Pesquisa Agropecuária Brasileira, v.35, n.9, p.1809-1816, 2000.

LAVRES JR., J.; MONTEIRO, F.A. Perfilhamento, área foliar e sistema radicular do capim-Mombaça submetido a combinações de doses de nitrogênio e potássio. Revista Brasileira de Zootecnia, v.32, n.5, p.1068-1075, 2003.

LIRA, M.A.; FARIAS, I.; FERNANDES, A.P.M. et al. Estabilidade de resposta do capim-braquiária (Brachiaria decumbes, Stapf.) sob níveis crescentes de nitrogênio e fósforo. Pesquisa Agropecuária Brasileira, v.29, n.7, p.1151-1157, 1994.

MACHADO, A.O.; CECATO, U.; MIRA, R.T. et al. Avaliação da composição química e digestibilidade in vitro da matéria seca de cultivares e acessos de Panicum maximum Jacq. sob duas alturas de corte. Revista Brasileira de Zootecnia, v.27, n.5, p.10571063, 1998.
MARSCHNER, H. Mineral nutrition of higher plants. 2.ed. London: Academic Press, 1995. 889p.

MONTEIRO, F.A. Nutrição mineral e adubação. In: SIMPÓSIO SOBRE MANEJO DA PASTAGEM, 12., 1995, Piracicaba, Anais... Piracicaba: Fundação Estudos Agrários Luiz de Queiroz, 1995. p.219-244.

QUADROS, D.G.; RODRIGUES, L.R.A.; FAVORETTO, V. et al. Componentes da produção de forragem em pastagens dos capins Tanzânia e Mombaça adubados com quatro doses de NPK. Revista Brasileira de Zootecnia, v.31, n.6, p.1333-1342, 2002.

RIBEIRO JR., J. Análises estatísticas no SAEG - Sistema de análises estatísticas e genéticas. Versão 8.1. Viçosa, UFV, 2001. 301p.

RIBEIRO, K.G.; GOMIDE, J.A.; PACIULlO, D.S.C. Adubação nitrogenada do capim-elefante cv. Mott. 2. valor nutritivo ao atingir 80 e $120 \mathrm{~cm}$ de altura. Revista Brasileira de Zootecnia, v.28, n.6, p.1194-1202, 1999.

SARMENTO, P.; RODRIGUES, L.R.A.; LUGÃO, S.M.B. et al. Sistema radicular do Panicum maximum Jacq. cv. IPR-86 Milênio adubado com nitrogênio e submetido à lotação rotacionada. Revista Brasileira de Zootecnia, v.37, n.1, p.27-34, 2008.

SILVA, D.J.; QUEIROZ, A.C. Analise de alimentos: métodos químicos e biológicos. 2.ed. Viçosa, MG: Imprensa Universitária, 2002. 235p. 